\title{
SOME IMPRESSIONS OF SUNGEI BULOH LEPER HOSPITAL UNDER JAPANESE OCCUPATION
}

Gordon A. Ryrie

On the 8th of January, 1942, Japanese troops occupied the area of Sungei Buloh Leper Hospital in the Federated Malay States. At that point there were 25Io lepers, including 265 children-Malays, Indians, Chinese, and a sprinkling of other nationalities. Thereafter all contact with the outer world ceased.

On the I6th September, I945-after the defeat of Japan and the re-entry of our forces into Malaya-the number of inmates was 660. The number of children left was 2I. The rest were dead.

For a number of reasons this tragic period does not yield a great deal of scientific interest. To begin with the Japanese carried off or destroyed all the scientific data of the Hospitalcase histories, sections, photographs and long term experimental work still awaiting completion. Much of this can never be replaced. In the second place it was impossible to keep scientific or accurate data under Japanese rule, and this for two reasons. All official figures were "cooked" in order to prove that public health was at least as good under the Japanese as under the British administration. For example, at an autopsy one might note the presence of grass in the stomach and intestines. But the inclusion of this finding in an official report would merely invite the attentions of the security police. The cause of death 
would therefore be marked down as "senility" or something equally innocuous. Then again the keeping of private statistics was inadvisable to say the least of it, under a regime where spying was constant, arbitrary search frequent, and where documents of any kind were regarded with extreme suspicion.

In the third place any assessment of changes in leprosy under the Japanese occupation is vitiated by the very complexity of factors involved. If, for instance, we examine a patient suffering from pellagra, chronic malaria, starvation and Gestapo psychosis, to what are we to attribute any changes in his leprotic condition?

The changes, leprotic and otherwise, were due in general to the impact of fear, famine and concurrent disease. To this must be added the sudden and continued deprivation of the means of treatment not merely anti-leprosy treatment, but such things as bandages, antiseptics, quinine and morphia.

The picture of Sungei Buloh during this period can only be appreciated against the background of Co-Prosperity in Greater East Asia, the slogan of Japanese conquest. This, as it applied to Malaya, can be divided into three phases. The first was a period of initial confusion. This gradually merged into a more or less stabilised condition of affairs-the period of organised robbery-during which the Japanese steadily stripped the country bare of all its realisable assets. When both the loot and the prospects of victory began to dwindle the frustrated Japanese instituted the third phase-the phase of the Gestapo. This division is to a considerable extent artificial. Confusion and corruption abounded all the time, and the trained thugs of the security police were active from the beginning. But a sequence can definitely be traced in which the predominant features were first chaos, then exploitation, then terrorism.

First let us consider Sungei Buloh during the period of chaos - the first months of Co-Prosperity. Undoubtedly the essential factor in the changes during this period was fear. Starvation was not in evidence. Food was variable, but the patients had probably about fifteen hundred calories a day. Concurrent disease had not yet come into its own, but the fear had a physical intensity that is difficult to describe with any degree of adequacy. On two occasions during this period I have seen a man drop dead in front of me in a paroxysm of terror. There was no electric light, no telephone, no post, no newspaper, no radio, and road communication was extremely perilous. This produced a kind of nightmare stillness punctuated by whooping raids of looting Jap soldiery, night attacks of bandits, to the accompaniment of rapid smallarms fire. "searches" - by brutal unfathomable military police 
-all in a tense atmosphere of spy-mania, betrayal, corruption and private crime. Suicide was frequent among the lepers during this period, mostly among the older men. Suicide was confined entirely to males.

As would be expected, loss of weight was general, the loss being entirely due, I think, to psychic dislocation. The weekly weighings shewed the loss to be most uneven. After being deeply affected by some particular incident, a patient might lose fourteen pounds or more in a week, and recover gradually with restoration of control. The weight-loss was very much less marked among the children, who did not appear to suffer significantly at this point.

The death rate rose to ten and fifteen times its normal peacetime level. During this period, for all practical purposes, all the significant anaemias, all the advanced nephritis cases, and all the active tuberculosis patients died. This represented a more or less complete group. They were the ten per cent or so of ailing and elderly people found in any non-selective leper settlement-folks who had looked forward in peace-time to their little extra issues of milk and oranges and tobacco, and whose placid and fragile lives could stand no strain.

The Japanese gradually settled down to a more or less organised stripping of the country. This phase lasted something over a year, or roughly as long as it was possible to get ships to carry the loot back to Japan. Food in the Settlement gradually became more scarce, the main article of diet being vegetables. Small quantities of first class protein-a few ounces per headcould be issued about once a month. The patients had, I estimate, about seven hundred calories a day. Deterioration on a low vegetable diet is rapid unless fats are added, and the main anxiety during this phase was the provision of cocoanut oil and ground nuts. From this time on we were greatly indebted to the Resistance Movement for essential supplies of food.

Up to this time the extreme danger of being abroad at or after dusk had probably delayed the onset of epidemic malaria. All anti-malarial work had, of course, broken down under the Japanese, who were equally lacking in interest, knowledge or ability: By the time the occupation was a year old two-thirds of the patients had malaria. The first wave of the epidemic was almost entirely M.T. and the proportion of cerebral cases was over five per cent. Most of these died. The price of quinine rose till it reached the fantastic figures of $£$ roo per lb. As quinine passed through the hands of Japanese officials, it became progressively adulterated, until doses of fifty and even a hundred 
grains had to be given to ensure that the patients had received ten grains of genuine quinine. Dressers, nurses and attendants automatically got malaria within a fortnight of being posted to the malarial wards, so that the physicians round became a sort of blurred reel in which it was difficult to differentiate between patients and staff. In any case, with the shortage of quinine, the main object of the "round" was to determine each day which of the patients were to be allowed to die. I have to record here a considerable number of cases in which men and women deliberately refused their quinine, and died in order that their sick comrades might live. It will be remembered that at this time the Japanese had control of the greater part of the world's supply of quinine.

The question of anti-leprosy treatment had already arisen. It must be explained that in peace time the whole emphasis of Sungei Buloh had been on treatment. Everything else had been subordinated to this. There were acute tuberculoid and acute lepromatous wards, and the patients were divided into clinical groups and classifications on which all organisation was based. Without counting intradermal work, there had been a thousand injections a day, and an average of fifteen miles of bandaging a month. Stoppage of treatment meant ripping away the whole fabric of the settlement. From an administrative point of view continuance was necessary for the morale of both patients and staff.

There was sufficient Hydnocarpus oil for about six weeks of peace-time treatment. The minimum pre-war injection dose of Hydnocarpus oil was I c.c. per ten pounds of body weight twice a week. By injecting token doses of Hydnocarpus oil the stocks could last for perhaps six months. But the war was obviously going to last longer than six months.

There was a further problem. The healthly staff were already badly undernourished and suffering from malaria. A small reserve of oil had to be kept in case any of them developed leprosy under conditions of strain and lowered resistance.

In the end a small group of patients with tuberculoid leprosy was kept on full peace-time doses of Hydnocarpus oil. The rest of the patients were given weekly one c.c. doses of " New Esters, War Time Formulary." The war-time formulary consisted of a I-5000 solution of Potassium Permanganate in water. We had thus an enforced " experiment" whereby a very large group of lepers was abruptly changed from high doses of hydnocarpus oil to a "treatment" which we knew to be useless. The results were as follows:- 
I. In peace time $150-200$ patients were discharged each year as " cured " (I use the word as a matter cf convenience). In the period under review no single patient became fit for discharge.

2. Within three or four months of the inception of the "New Esters " the patients wcre unanimous in declaring that the new treatment was useless, and in demanding the restitution of Hydnocarpus oil. It will be recalled that the patients belonged to shrewd and highly intelligent races, and that they had considerable experience of anti-leprosy treatment.

3. The twenty-five tuberculoids on Hydnocarpus oil compared very favourably with other tuberculoids on "New Esters". In no case, however, did the clinical improvement equal that to be expected in peace-time.

It is obviously open to question whether any kind of antileprosy treatment could be anything but a solemn farce under the conditions prevailing at the time. It may also be claimed that, in a state of malnutrition, the metabolic value of Hydnocarpus oil may constitute its only value. But yet, when all criticisms are conceded, these years convinced me as nothing else has done, of the real (I avoid the word 'specific') value of Hydnocarpus oil. With adequate stocks of oil I believe that a great deal of the ulceration and spread of leprosy could have been averted.

During peace time there were roughly a hundred cases a month of lepromatous reaction in the hospital wards. The number of cases of tuberculoid reaction was perhaps twenty a month. There were another thirty or forty cases a month of nerve reaction, or acute leprotic neuralgia.

During the Japanese occupation there could not have been more than two or three cases a month of lepromatous reactionsay three per cent. of the peace-time figure. There were, so far as I can recall, no cases of tuberculoid reaction or of leprotic neuralgia. For all practical purposes the acute manifestations of any kind of leprosy disappeared. Peace-time investigation had previously shown that the incidence of reaction was not connected with the high doses of Hydnocarpus oil.

The suppression of acute tuberculoid leprosy is perhaps understandable. It is a common finding that a certain type of tuberculoid lesion tends to fade during concurrent illness and reappears (as in " recovery reaction") when health improves. (For practical purposes we may regard the Japanese occupation as one long concurrent illness). We assume that tuberculoid manifestations are allergic phenomena, affected by antibody which is released under conditions of increased general resistance. 
The absence of lepromatous reaction is more difficult to understand. Indeed it is very difficult to think of any analogy in disease in which an acute invasive process, with fever and baciliaemia, is inhibited by the very defencelessness of its victim. There is certainly no analogy in tuberculosis or in the common infectious diseases.

Following the period of confusion and that of exploitation came the Gestapo phase. It was natural. The Wingate attack coming on top of the strangulation of their home communications had rendered the Japanesc apprehensive. Their Indian Independence League was a failure, the Resistance Movement was growing, and everywhere the down trodden people were sick of the slow necrosis of CD-Prosperity. And so the reign of terror began.

The object of Gestapo rule was to induce a continuous state of apprehension resulting in a kind of abject masochism. It was more successful with some races and types than with others. The psychological effects of Gestapo rule, however, interesting and revealing as they were, do not concern us so much as the physical results of this phase. These were the retardation of healing and the breakdown of leprotic tissue, the spread of deficiency disease, and the onset of uncontrolled sepsis.

While malnutrition and vitamin deficiency will in themselves delay healing, it will be remembered that psychogenic factors can play an important role. Healing may be regarded from one point of view as essentially a defiance of environment. When that defiance has been crushed out of the human spirit, the deficiency can affect every cell in the body. We speak of healing by "intention". There came a phase in cases affected by nervous strain and famine when "intention" disappeared. A patient might bruise his foot, the skin of which was already infiltrated with leprosy. There would be no attempt at healing. The bruise would slowly decay and the decay spread to the surrounding devitalised tissues. The analogy of a bruised apple was one that constantly recurred to the mind. Spreading sores of this character probably affected some fifteen per cent of the leper population. It was less marked among the Chinese.

Cases of beri-beri and pellagra began to occur during this third phase. Both were markedly atypical. Orthodox wet or dry beri-beri was not observed. One difficulty in diagnosis was that drop-foot and anaesthesia occur in both beri-beri and leprosy. The main features observed were lassitude, numbness of the finger tips (unexplained by the leprotic condition) and loss of 
undion reflexes. Between five and ten per cent of the patients showed signs of Vitamin 13 deficiency.

Pellagrous manifestations were also atypical, for as far as onc could judge in the circumstances there was no mental abnormality and no specific diarrhoea. The first case observed in the Settlement was of some diagnostic interest. A chronic lepromatous ( $\mathrm{L}_{3}$ ) case was reported to have developed a fresh tuberculoid batswing lesion across the nose. I stated dogmatically at the time that such a lesion combination was impossible in any coherent view of the leprotic process. The diagnosis was finally made by the discovery of definite pellagrinous lesions on the patient's feet.

Pellagra is unlikely to be confused with leprosy where only the one lisease is present in a given case. But pellagrinous lesions on a tuberculoid leper can be difficult to differentiate. They may resemble tuberculoid plaques quite closely, and in my experience they are often faintly anaesthetic on the hands and feet.

I have already mentioned the cessation of intention in healing, a condition in which the body ceases to defend its own frontiers. This forms an ideal breeding ground for sepsis, and during this period sepsis became uncontrolled. The tiny remaining stocks of effective antiseptics, cotton wool and dressings had to be reserved for use in major operations. Septic cases were therefore treated with local applications of various jungle concoctions (all equally useless) and bandages of banana leaves. There resulted a rapid spread of sepsis under pre-Listerian conditions among devitalised lepers affected by famine and strain.

It will be sufficient to give the very briefest picture of a ward in Sungei Buloh on any given day in the autumn of 1943. On entrance the smell struck one like a physical wave. The air was filled with a fine gummy exudation that clung to the eyes, nostrils and forearms. The floor was criss-crossed with trails of pus where patients had staggered about. Patients moaned for poison. Under the beds were pools of pus, blood and urine. Mattresses had long disappeared and the bedboards creakedrotten through with encrusted pus. A patient would bruise his toe. The next day half the foot would be grey-black and putrifying. The next day the ankle would be affected, and an incision near the head of the fibula would release frothy pus travelling along the interfascial sheaths. The next day he would be dead. Patients pleaded for operation, not with any hope, but for the luxury of dying without being submerged in their own foetor. By the beginning of 1944 half the patients were dead.

It may be asked why the Japanese did not exterminate the 
lepers. They certainly threatened to do so with a regularity that never became monotonous. Indeed I canot recall a week during which they did not threaten to bomb-out or machine gun the whole settlement, The reason why the Japanese confined themselves to threats is simply told. The leper settlement contained patients from all over the Federated Malay States. Under the British regime these various states paid so much per head per day for their lepers maintained at Sungei Buloh. This payment was continued under the occupation for the Japanese, terrified of infectious disease, would rather levy money than risk the return of lepers to their various districts. Except for a token payment for the maintenance of. Sungei Buloh this money was retained by the local Japanese Governor for his own use. It will be realised that if he retained one shilling per head per day (which is about correct) for a thousand patients, he was making a profit of fifteen hundred pounds per month. And so the lepers were spared-they were profitable.

When the end came the hospital wards were empty, for no-one was left able to care for the sick. Like wraiths over the untended paths, the patients came out of their houses with uncertain eyes and waivering gait, to welcome their liberators. 